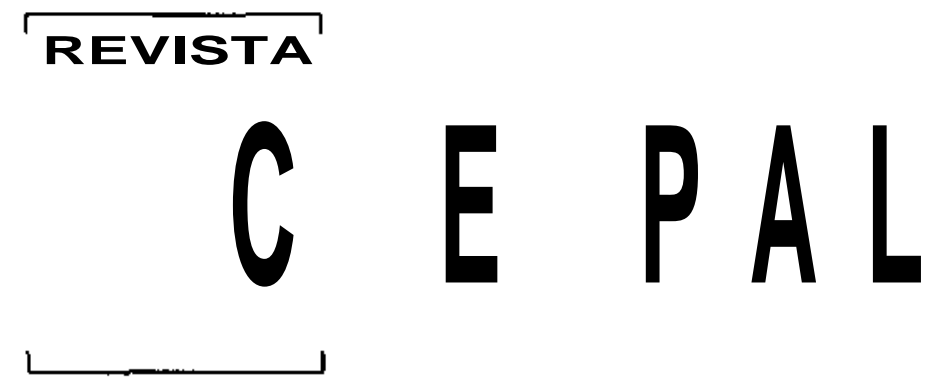

NUMERO 65

AGOSTO 1998

SANTIAGO DE CHILE

ÓSCAR ALTIMIR

Director

EUGENIO LAHERA

Secretario Técnico

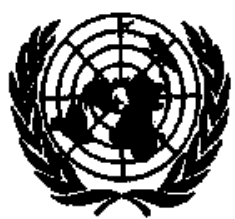

NACIONES UNIDAS 
Distribución del ingreso, pobreza y gasto social en América Latina José Antonio Ocampo

Gasto militar y el desarrollo en América Latina

Eugenio Lahera y Marcelo Ortúzar

Crecimiento, justicia distributiva y política social

Andrés Solimano

Equidad, inversión extranjera y competitividad internacional

Adolfo Figueroa

Tensiones en el ajuste estructural en América Latina: asignación vs. distribución

Daniel M. Schydlowsky

Competitividad y regulaciones laborales

Luis Beccaria y Pedro Galín

Familias latinoamericanas: convergencias y divergencias de modelos y políticas

Irma Amagada

Los acuerdos de libre comercio y el trabajo de las mujeres:

el caso de Chile

Alicia Frohmann y Pilar Romaguera

Evolución macroeconómica del Paraguay 1989-1997:

burbuja de consumo y crisis financiera

Stéphane Straub

Estrategias de las empresas mexicanas en sus procesos de internacionalización

Alejandra Salas-Porras

La regulación de la prestación privada de servicios de agua potable y alcantarillado

Terence R. Lee y Andrei S. Jouravlev

Promoción de la calidad para mejorar la competitividad

Hessel Schuurman

Publicaciones recientes de la CEPAL 


\section{Evolución macroeconómica del Paraguay 1989-1997: burbuja de consumo y crisis financiera}

\section{Stéphane Straub}

Asesar del Ministro Secretario Ejecutivo de Planificación, Presidencia de la República del Paraguay
El artículo examina la evolución macroeconómica del Paraguay después de 1989, fecha crítica pues marca el retorno a la democracia y el viraje hacia una liberalización de la economía. El proceso de estabilización emprendido entonces se tradujo en una evolución favorable de las variables monetarias, pero no así de la inversión y del crecimiento del producto. La combinación de cuantiosas entradas de capitales y el aumento excesivo de la demanda agregada generó un creciente desequilibrio externo reflejado en una burbuja de consumo interno. El comercio no registrado, característica peculiar de la economía paraguaya, incide en la evolución del cuadro macroeconómico y al parecer ha contribuido a agravar las tendencias mencionadas, pues también hasta 1994 hubo déficit en ese comercio. En el sector financiero el proceso de liberalización no se acompañó de un fortalecimiento de la supervisión bancaria. En este contexto permisivo, el sector financiero contribuyó a la burbuja de consumo de los años noventa, a través de la proliferación de actividades riesgosas, de préstamos vinculados y del rápido crecimiento de un sector financiero informal o "negro". La fragilización resultante de muchas entidades financieras explica que una conjunción de perturbaciones internas y externas provocara en 1995 una crisis financiera que tuvo efectos recesivos sobre toda la economía. El descuido de elementos tan fundamentales como la vigilancia del exceso de gasto y la modernización de la supervisión bancaria, y la opción equivocada por un modelo importador y de comercio informal, facilitaron el aprovechamiento de una cuasi renta de privilegio por determinados grupos de interés y la formación de burbujas de consumo que contribuyeron a la crisis. Se precisa entonces una política macroeconómica sostenible y orientada al crecimiento, sobre la base de un proceso de innovación genuino. 


\section{I}

\section{Introducción}

La evolución económica del Paraguay después del retorno a la democracia en 1989 muestra rasgos favorables. En todos los años noventa, el país mantuvo un balance fiscal satisfactorio. La inflación se redujo progresivamente hasta alcanzar una tasa de un solo dígito en 1996, subió el nivel de las reservas internacionales y bajó la deuda pública externa hasta representar en 1996 alrededor del 14\% del producto interno bruto (PIB), el menor nivel relativo en América Latina. En cambio, fue escaso el crecimiento del producto y se estancó el PIB per cápita.

Paralelamente, fueron apareciendo varios problemas, como ocurría en otros países de la región. En el plano macroeconómico, la menor tasa de inflación se logró gracias a una política de vigilancia de la masa monetaria y de ancla cambiaría, acompañada de una estrategia de austeridad fiscal, pero se descuidaron aspectos tan fundamentales como la demanda agregada, variable que registró tasas elevadas de crecimiento en el período. Esta situación generó desequilibrios externos crecientes, con un crecimiento medio anual de las importaciones muy superior al de las exportaciones. Estas importaciones, por su parte, se componían en proporción cada vez mayor de bienes de consumo.

Como corolario, en la primera parte de la década hubo una creciente entrada de capitales volátiles. En estas condiciones, en que al aumentar la demanda interna caía el ahorro interno, reemplazado progresivamente por el ahorro externo, se estancó la formación bruta de capital fijo y resultó insostenible el nivel de absorción alcanzado.

La sección II de este artículo analiza esta evolución y el comportamiento de las principales variables macroeconómicas; muestra cómo los elementos mencionados han contribuido a la formación de una burbuja de consumo, volviendo inevitable una contracción futura, como la que ocurrió en 1995.

En la sección III, se examina la tesis según la cual el exceso de bienes importados y la aparente diferencia entre el gasto interno y el PIB serían en realidad consecuencia del comercio de reexportación tradicional del Paraguay, en el cual se registraban los bienes importados para su posterior venta al exterior pero no se registraban esas reexportaciones. Se muestra que las distintas estimaciones disponibles invalidan en gran parte esta explicación, y que incluso parece haberse dado también un déficit en el comercio no registrado, al quedarse una parte de las importaciones no registradas en el país en vez de ser reexportadas, alimentando así la burbuja de consumo interno.

La sección IV examina las condiciones del sistema financiero resultantes de la liberalización iniciada a principios de los años noventa. Esta liberalización se llevó a cabo en un contexto de débiles normas de regulación prudencial y escasa eficacia en la supervisión de su cumplimiento, con un Banco Central que gozaba de poca autonomía defacto. En ese medio, proliferaron las prácticas fraudulentas y ios malos manejos administrativos, amparados en la escasa fiscalización ejercida por las autoridades de tutela. A la vez, la situación dicotómica del sistema financiero, en el que coexistían entidades sanas y eficientes con otras cuyas prácticas no respondían a las normas de buen manejo, se tradujo en el mantenimiento de altas tasas de interés durante todo el período y en el racionamiento del crédito a una parte del sector productivo, específicamente a las empresas pequeñas y medianas no vinculadas con algún grupo bancario.

El fenómeno de burbuja de consumo se reflejó en la esfera financiera en una bonanza de crédito (sin prejuzgar del sentido de causalidad entre los dos fenómenos) que alcanzó a todo el sistema financiero, aunque más marcadamente al segmento de la banca de capital nacional. La situación fue agravada por importantes entradas de capital atraídas por las altas tasas de interés vigentes. Por la debilidad de los controles, éstas alimentaron el auge del crédito al consumo, a actividades financieras especulativas y de corto plazo, a operaciones en el sector informal y a la especulación inmobiliaria, entre otros, lo que generó una concentración excesiva de la actividad económica en sectores de alto riesgo y escasa generación de valor agregado. Esta acumulación de carteras riesgosas, facilitada por la garantía implícita del Estado a los depósitos y la escala que alcanzaron las malas prácticas, parecen ser responsables en gran parte de las quiebras bancadas ocurridas a partir de 1995.

En la medida en que las entidades tenían una situación patrimonial debilitada por numerosas operaciones riesgosas, no registradas - generalmente realizadas a tasas de interés muy elevadas-, por préstamos 
vinculados, etc., fueron las primeras en verse afectadas por una serie de sucesos en 1995, entre los cuales figuraron la caída de los precios internacionales de la soja, la reversión parcial de los flujos de capitales y un escándalo financiero interno. La crisis financiera iniciada en 1995 es considerada como un proceso de saneamiento en el que un choque externo impuso al sistema bancario una tensión excesiva y lo llevó a una ruptura de sus eslabones más frágiles, en este caso las actividades de alto riesgo y/o ilegales. A través de su impacto sobre el sistema de crédito informal, esa crisis financiera repercutió sobre toda la economía y generó un ajuste recesivo importante.

A la luz de lo analizado, se plantean a modo de conclusión las líneas directrices de un programa de política macroeconómica sostenible para el Paraguay, orientado no sólo a la estabilización, sino también al crecimiento. Por último, se advierte, como base para un futuro análisis, que el fenómeno de burbuja observado puede caracterizarse como consecuencia del aprovechamiento de lo que Nochteff (1996) llama "cuasi rentas de privilegio", sistema en el que grupos de interés dominantes aprovechan su influencia en las instituciones para perpetuar esas rentas en los distintos niveles (sistema importador de contrabando y reexportación, especulación financiera e inmobiliaria). Este fenómeno frenó en muchos casos la búsqueda de cuasi rentas tecnológicas que hubiesen impulsado el desarrollo a base de la innovación y la generación de ventajas competitivas genuinas.

\section{II}

\section{Escenario macroeconómico de los años 90}

Entre 1989 y 1997 la evolución de los indicadores macroeconómicos en el Paraguay muestra el resultado de la política de estabilización iniciada en el nuevo ambiente de liberalización y de saneamiento que acompañó el retorno a la democracia. En particular, durante el período, el manejo fiscal fue satisfactorio (el déficit del gobierno central nunca superó $0.8 \%$ del PIB, mientras que el sector público no financiero se mantuvo superavítario en todo el periodo) y la tasa de inflación se redujo progresivamente luego del máximo que alcanzó en 1990 (cuadro 1).

Varios sectores de la economía fueron liberalizados. El tipo de cambio, hasta entonces múltiple y sujelo a manipulaciones políticas, fue reemplazado por un tipo de cambio único flotante. Las tasas de interés fueron liberadas y se autorizaron las operaciones en moneda extranjera. El manejo de la política monetaria fue saneado, eliminándose después de 1990 el redescuento automático a determinados sectores ${ }^{1}$ (el algodón en particular) y la posibilidad de un financiamiento monetario del sector público. Durante el período se acumularon reservas internacionales que a fines de 1996 sumaban 1062 millones de dólares - equivalentes a 2.4 meses de importaciones de bienes y

\footnotetext{
1 Sin embargo, la supresión del redescuento no fue total, pues como se explica en la sección IV, hasta 1994 rigió un mecanismo de redescuento indirecto a través de la reducción de encajes, ligado al financiamiento del algodón.
}

servicios- y se redujo el peso de la deuda pública externa; en 1997 ésta llegó a 14\% del PIB, cifra muy baja para los estándares de la región (cuadro 1). A pesar de estos indicadores favorables, el crecimiento real de la economía fue insuficiente; promedió $3.1 \%$, cifra apenas superior al crecimiento poblacional estimado entre 2.7 y $3 \%$, con lo que el PIB per cápita se estancó.

La política monetaria aplicada a partir de 1991 podría describirse como de "bianclaje": en la cantidad de dinero y en el tipo de cambio. El esquema del Banco Central apunta — sin gran éxito- a mantener un crecimiento moderado de los agregados monetarios (cuadro 2) y a la vez a un tipo de cambio administrado (dirty float). Esta política terminó haciendo más hincapié en el segundo elemento, ya que a las autoridades monetarias les era difícil vigilar la masa monetaria en una economía con ingentes operaciones financieras no registradas, parcialmente dolarizada y sin posibilidades reales de controlar los movimientos de divisas dentro y fuera del país. En consecuencia, el anclaje parcial del tipo de cambio se tradujo en una importante diferencia entre las variaciones de los precios de los bienes transables y de los no transables y en una apreciación cambiaría importante (cuadro 3).

La política fiscal fue utilizada principalmente como sostén de la estrategia monetaria, con superávit forzosos congelados en el Banco Central, lo que explica los buenos resultados presupuestarios. Sin embar- 
CUADRO 1

Paraguay: Indicadores generales, 1989-1996

(Millones de dólares corrientes, salvo indicación contraria)

\begin{tabular}{|c|c|c|c|c|c|c|c|c|c|}
\hline & 1989 & 1990 & 1991 & 1992 & 1993 & 1994 & 1995 & 1996 & 1997 \\
\hline PIB & 4115 & 5285 & 6254 & 6447 & 6841 & 7857 & 8970 & 9686 & 10029 \\
\hline PIB (millones de dólares de 1982) & 6614 & 6818 & 6987 & 7113 & 7407 & 7636 & 7996 & 8097 & 8311 \\
\hline PIB per cápita (dólares de 1982) & 1618 & 1616 & 1612 & 1597 & 1619 & 1625 & 1656 & 1634 & 1634 \\
\hline Crecimiento del PIB (\%) & 5.8 & 3.1 & 2.5 & 1.8 & 4.1 & 3.1 & 4.7 & 1.3 & 2.6 \\
\hline Sup. (+)/def. $\{-)$ fiscal del gob. central & 100 & 158 & -19 & -18 & -48 & 75 & -25 & -76 & -0.8 \\
\hline En $\%$ del PiB & 2.4 & 3.0 & $-0,3$ & -0.3 & -0.7 & 1.0 & -0.3 & -0.8 & -0.8 \\
\hline \multicolumn{10}{|l|}{ Sup,(+)/def.(-) fiscal del sector público } \\
\hline no financiero & 79 & 276 & 98 & 60 & 83 & 191 & 228 & 167 & $\cdots$ \\
\hline En $\%$ del PIB & 1.9 & 5.2 & 1.6 & 0.9 & 1.2 & 2.4 & 2.5 & 1.7 & $\ldots$ \\
\hline Reservas monetarias & 427 & 675 & 975 & 611 & 698 & 1044 & 1107 & 1062 & 800 \\
\hline Deuda externa & 2076 & 1670 & 1637 & 1249 & 1217 & 1240 & 1328 & 1336 & 1413 \\
\hline Deuda/exportaciones de bienes & & & & & & & & & \\
\hline y servicios $(\%)$ & 148 & 89 & 81 & 66 & 44 & 36 & 30 & 32 & 37 \\
\hline Inflación (\%) & 28.5 & 44.1 & 11.8 & 17.8 & 20.4 & 18.3 & 10.5 & 8.2 & 6.2 \\
\hline
\end{tabular}

Fuente : Elaboración propia sobre la base de cifras oficiales del Banco Central y del Ministerio de Hacienda del Paraguay.

CUADRO 2

Paraguay: Evolución de los agregados monetariosi e inflación, 1989-1996

(Variación interanual a diciembre, en porcentajes)

\begin{tabular}{lcccccccr}
\hline & 1989 & 1990 & 1991 & 1992 & 1993 & 1994 & 1995 & 1996 \\
\hline Base monetaria & 27.2 & 21.4 & 25.7 & 31.2 & 16.8 & 27.4 & 23.0 & 3,2 \\
MI & 46.1 & 27.6 & 27.4 & 28.5 & 19.3 & 32.8 & 20.3 & 2.0 \\
M2 & 41.5 & 28.1 & 35.4 & 28.4 & 15.3 & 38.5 & 34.8 & 13.3 \\
M3 & 75.6 & 36.0 & 41.1 & 39.8 & 28.7 & 28.7 & 22.9 & 21.9 \\
Inflación & 28.5 & 44.1 & 11.8 & 17.8 & 20.4 & 18.3 & 10.5 & 8.2 \\
\hline
\end{tabular}

Fuente : Elaboración propia con cifras del Banco Central del Paraguay.

CUADRO 3

Paraguay: Evolución de los precios relativos, 1990-1996

(Bienes transables/bienes no transables, 1990-100)

\begin{tabular}{lr}
\hline 1990 & 100 \\
1991 & 95.2 \\
1992 & 93.8 \\
1993 & 91.1 \\
1994 & 88.6 \\
1995 & 87.4 \\
1996 & 80.0 \\
\hline
\end{tabular}

Fuente: Elaboración propia con datos del Banco Central del Paraguay.

go, esto se logró a costa del recorte sistemático de las inversiones en infraestructura, que se convirtieron en la variable de ajuste del gasto fiscal. Al no haber adoptado el país una política decidida de privatización o de tercerización de las obras públicas, se agravó aún más el rezago en cuanto a infraestructura, lo que probable- mente contribuye a explicar el lento crecimiento observado en lo que va de los años noventa, ${ }^{2}$ Paralelamente, el país no fue ajeno al proceso de retorno del financiamiento externo que se daba en toda la región (Ffrench-Davis, 1996; Aninat y Larraín, 1996): a partir de 1990 se registraron importantes entradas de capitales, principalmente de corto plazo (cuadro 4, línea 9). A la vez hubo una marcada reducción del ahorro interno (en especial de los hogares), lo que desembocó en un fuerte crecimiento del gasto de consumo, con un alto componente de bienes importados.

Parte de la afluencia de capitales descrita alimentó la acumulación de reservas. La tasa de inversión se estancó alrededor de su nivel inicial de $23 \%$ del PIB durante todo el período; además, su composición - con excesivo predominio de la construcción- hizo

\footnotetext{
${ }^{2}$ Véase un examen de la situación de la infraestructura en el continente en Banco Mundial, 1996.
} 
Paraguay: Indicadores macroeconómicos, 1989-1996

\begin{tabular}{|c|c|c|c|c|c|c|c|c|}
\hline & \multicolumn{8}{|c|}{ A. En millones de guaraníes de 1982} \\
\hline & 1989 & 1990 & 1991 & 1992 & 1993 & 1994 & 1995 & 1996 \\
\hline 1. Producto interno bruto & 899500 & 927317 & 950208 & 967312 & 1007377 & 1038547 & 1087409 & 1101 \\
\hline 2. Ingreso nacional bruto & 865321 & 899381 & 913048 & 925581 & 967657 & 1001577 & 1044539 & 1066832 \\
\hline 3. Consumo $\{4+5)$ & 669245 & 753036 & 780600 & 836997 & 881575 & 999299 & 1034007 & 1059270 \\
\hline 4. Público & 64639 & 66707 & 80047 & 86288 & 90847 & 94382 & 105772 & 116349 \\
\hline 5. Privado & 604606 & 686329 & 700553 & 750709 & 790728 & 904917 & $928 \quad 235$ & 942921 \\
\hline 6. Inversión & 200747 & 219175 & 238030 & 222482 & 227557 & 237699 & 254588 & 254311 \\
\hline $\begin{array}{l}\text { 7. Exceso de gasto sobre } \\
\text { el PIB }(3+6-1) \\
\text { 8. Exceso de gasto sobre }\end{array}$ & -29508 & 44894 & 68422 & 92167 & 101755 & 198451 & 201186 & 212423 \\
\hline el $\operatorname{INB}(3+6-2)=11$ & 4671 & 72830 & 105582 & 133898 & 141475 & 235421 & 244056 & 246749 \\
\hline 9. Afluencia neta de capitales & 36437 & 111342 & 151037 & 81823 & 154169 & 278748 & 238549 & 241671 \\
\hline 10. Cambios en las reservas & 31766 & 38512 & 45455 & -52075 & 12694 & 43327 & 5782 & -5078 \\
\hline \multirow[t]{3}{*}{ II. Ahorro externo $(9-10)=8$} & 4671 & 72830 & 105582 & 133898 & 141475 & 235421 & 244056 & 246749 \\
\hline & \multicolumn{8}{|c|}{ B. En porcentajes del PIB } \\
\hline & 1989 & 1990 & 1991 & 1992 & 1993 & 1994 & 1995 & 1996 \\
\hline 1. Producto interno bruto & 158 & 100 & 100 & 100 & 100 & 100 & 100 & 100 \\
\hline 2. Ingreso nacional bruto & 96.2 & 97.0 & 96.1 & 95.7 & 96.1 & 96.4 & 96.1 & 96.9 \\
\hline 3. Consumo $(4+5)$ & 74.4 & 81.2 & 82.2 & 86.5 & 87.5 & 96.2 & 95.1 & 96.2 \\
\hline 4. Público & 7.2 & 7.2 & 8.4 & 8.9 & 9.0 & 9.1 & 9.7 & 10.6 \\
\hline 5. Privado & 67.2 & 74.0 & 73.7 & 77.6 & 78.5 & 87.1 & 85.4 & 85.6 \\
\hline 6. Inversión & 22.3 & 23.6 & 25.1 & 23.0 & 22.6 & 22.9 & 23.4 & 23.1 \\
\hline $\begin{array}{l}\text { 7. Exceso de gasto sobre } \\
\text { el PIB }(3+6-1) \\
\text { 8. Exceso de gasto sobre }\end{array}$ & -3.3 & 4.8 & 7.2 & 9.5 & 10.1 & 19.1 & 18.5 & 19.3 \\
\hline el INB $(3+6-2)=11$ & 0.5 & 7.9 & 11.1 & 13.8 & 14.0 & 22.7 & 22.4 & 22.4 \\
\hline 9. Afluencia neta de capitales & 4.1 & 12.0 & 15.9 & 8.5 & 15.3 & 26.8 & 21.9 & 21.9 \\
\hline 10. Cambios en las reservas & 3.5 & 4.2 & 4.8 & -5.4 & 13 & 4.2 & 0.5 & -0.5 \\
\hline 11. Ahorro externo $(9-10)=8$ & 0.5 & 7.9 & 11.1 & 13.8 & 14.0 & 22.7 & 22.4 & 22.4 \\
\hline
\end{tabular}

Fuente: Elaboración propia con cifras de cuentas nacionales y balanza de pagos.

que la eficiencia de la formación bruta de capital fijo fuera baja, según muestra la elevada relación capitalproducto incremental de 9.5 para el período 1990-1996 y de 6.9 si se exceptúan los dos años de crecimiento más bajo (Moon, 1997), que casi equivale al de países desarrollados. ${ }^{3}$ Cabe señalar que los grandes inversores institucionales (el Instituto de Previsión Social y las otras cajas de pensiones) han dirigido tradicionalmente la mayoría de sus fondos a empresas inmobiliarias, contribuyendo así a limitar los recursos para inversiones productivas.

Es muy probable que la política de estabilización y el sesgo contra la producción local de bienes transa-

\footnotetext{
3 Una relación capital-producto incremental más elevada significa que es necesaria una formación bruta de capital más importante para elevar el crecimiento del PIB en un monto determinado. El valor observado en el caso del Paraguay es superior al de otros países con un nivel de ingreso similar.
}

bles, que resultaba de la tendencia a la sobrevaluación cambiaría, además de frenar la formación de capital fijo hayan generado una importante subutilización de la capacidad productiva existente y explique en parte las mediocres tasas de crecimiento del sector secundario durante el período.

Otro rasgo característico del proceso de estabilización fue la falta de seguimiento de la evolución de la demanda agregada y, por lo tanto, de la brecha gasto-producto en los últimos años. Esta última exhibió grandes fluctuaciones con relación al PIB y también al ingreso nacional bruto (INB), variable que representa la suma de que disponen los agentes de un país para gastar en un período determinado.

El rápido aumento de la brecha gasto-producto en los años noventa indica que no se vigiló suficientemente la evolución del gasto interno y su compatibilidad con la política económica del país. Así, entre 1990 y 
1995 el consumo interno creció 37.3\%, cifra que resulta de ponderar el crecimiento del consumo privado (35.2\%) y el del consumo público (58.6\%), mientras que el PIB crecía sólo en $17.3 \%{ }^{4}$

Como consecuencia de la apreciación cambiaría y del importante aumento de la demanda, hubo un creciente déficit en el comercio registrado. Durante el período 1989-1995, las importaciones crecieron en promedio $23 \%$ al año, mientras que las exportaciones mostraban un decrecimiento tendencial del $2 \%$. Este fenómeno es similar a lo acontecido en América Latina en general, ya que gran parte de la recuperación de la demanda en la región en los años noventa fue satisfecha por mayores importaciones. De hecho, los países que no hicieron tempranamente las correcciones adecuadas, como Argentina y México, tuvieron luego ajustes recesivos traumáticos (Ffrench-Davis, 1996).
Más interesante aún es lo sucedido con la composición de las importaciones. A partir de 1990, ésta se modificó sensiblemente y la participación de las importaciones de bienes de capital disminuyó, de $47.6 \%$ en ese año, a $32.3 \%$ en 1996, mientras que la participación de las importaciones de bienes de consumo se elevó de 26.4 a $44.6 \%$ en el mismo período (cuadro 5)

Sin embargo, las características propias del comercio exterior paraguayo, que en los años noventa incluyó una proporción cada vez mayor de comercio no registrado, llevó a muchos observadores a subestimar los efectos de la situación descrita en el desempeño macroeconómico del país. Prevaleció la noción de que el exceso de gasto observada o, lo que es lo mismo, los déficit comercial y corriente ${ }^{5}$ eran sólo aparentes y estaban en realidad compensados por un superávit en el comercio no registrado.

CUADRO 5

Paraguay: Composición de las importaciones por tipo de bienes, 1990-1996

(Porcentajes del total)

\begin{tabular}{lrrrrrrr}
\hline & 1990 & 1991 & 1992 & 1993 & 1994 & 1995 \\
\hline Bienes de consumo & 26.4 & 32.1 & 42.5 & 42.5 & 43.4 & 46.8 & \\
$\quad$ No duraderos & 20.6 & 25.1 & 29.2 & 29.5 & 30.9 & 34.3 & 34.6 \\
$\quad$ Duraderos & 5.8 & 7.0 & 13.3 & 13.0 & 12.5 & 12.5 & 8.3 \\
Bienes intermedios & 26.0 & 24.8 & 24.9 & 23.0 & 21.3 & 18.1 & 23.0 \\
Bienes de capital & 47.6 & 43.1 & 32.6 & 34.5 & 35.3 & 35.0 & 32.3 \\
\hline
\end{tabular}

Fuente; Elaboración propia con cifras del Banco Central del Paraguay.

III

\section{Déficit externo y comercio} no registrado: una apreciación

El comercio exterior del Paraguay se ha caracterizado en las últimas décadas por su importante componente de comercio no registrado. A la situación geográfica particular de medíterraneidad del país se suman otros factores para explicar la aparición de este tipo de comercio: por ejemplo, estrecha relación con el Brasil,

\footnotetext{
${ }^{4}$ En este caso se ha considerado el subperíodo 1989-1995, porque la crisis financiera ocurrida en mayo de 1995 modificó las tendencias del consumo y de la inversión y llevó a una caída del crecimiento global en 1996.
}

altos niveles arancelarios sin que éstos se acompañen de una política de sustitución de importaciones, tipos de cambio múltiples y un poder político complaciente, en la dictadura, con ciertos grupos de interés (Masi, 1995). El intercambio no registrado, que en los años setenta y ochenta consistía principalmente en impor

\footnotetext{
5 Las identidades contables de las cuentas nacionales dan cuenta de que el déficit comercial es igual al exceso de gasto con respecto al PIB, mientras que el déficit en cuenta corriente corresponde al exceso de gasto con respecto al ingreso nacional bruto (INB).
} 
taciones de contrabando desde el Brasil, se amplió a mitad de este último decenio con la aparición del llamado comercio de reexportación, sustentado en la alta protección existente en Brasil y Argentina ante las importaciones de productos terminados como alcoholes, cigarrillos, artículos electrónicos, perfumes, calzado deportivo, etc. Esto generó una nueva corriente de triangulación de productos provenientes de los países asiáticos y en menor medida de los Estados Unidos, los que son reexportados a los países vecinos. Asimismo, debido a los altos impuestos internos brasileños, se suele introducir en Paraguay mercadería (cigarrillos, ropas, etc.) desde Brasil para su posterior reexportación por los sacoleiros a ese mismo país. ${ }^{6}$

En 1989 se validó oficialmente el modelo reexportador informal, disponiendo rebajas arancelarias a los llamados "bienes de turismo" y en 1991, en el marco de la reforma tributaria, se otorgó un IVA preferencial a estos mismos productos (2\% en vez del $10 \%$ uniforme vigente). Finalmente, en 1995 se incluyó un gran número de estos "bienes de turismo" en las listas de excepciones del MERCOSUR, que para el Paraguay constan de 399 productos cuyos aranceles deben converger en un plazo de 5 a 10 años hacia el arancel externo común de $10 \%$.

En lo que toca al impacto macroeconómico de esta situación, cabe intentar una estimación de los flu-

6 Se llama sacoleiros a las personas que cruzan a pie el Puente de la Amistad entre Ciudad del Este (Paraguay) y Foz de Iguaçu (Brasil) llevando las mercaderías en grandes bolsas. El movimiento incesante de los sacoleiros da cuenta de gran parte de las "reexportaciones" hacia el Brasil. jos de comercio no registrados, considerando estimaciones dadas a conocer por el Banco Central del Paraguay y elaboradas sobre la base de cifras de la Dirección de Comercio del Fondo Monetario Internacional (cuadro 6). Al aislar en la fuente oficial el balance del comercio no registrado se ve que, contrariamente a lo que suele creerse, este rubro tuvo déficit entre 1989 y 1993, y sólo exhibió un saldo claramente positivo a partir de 1995.

La conclusión es polémica, pues prevalece la noción de que el comercio no registrado ha sido tradicionalmente superavitario. Sin embargo, además de las estimaciones mencionadas, dos hechos apoyan la idea de que el comercio no registrado fue deficitario hasta 1994 y de que esto se revirtió a partir de 1995. En primer lugar, 1995 marcó el inicio del ciclo recesivo en Paraguay (es decir, el momento en que la demanda interna se contrae y se reduce por lo tanto la demanda de importación) y del Plan Real en Brasil, que generó un auge de consumo (entre otros, de bienes importados) a través de la estabilización de precios y la apreciación de la moneda local. En segundo lugar, es hecho conocido que gran parte de las importaciones no registradas desde el Brasil corresponden a "contrabando" de productos alimenticios, de higiene, insumos para la construcción, etc., destinados al consumo interno y que este comercio prosperó principalmente hasta 1994 gracias a las condiciones cambiarías favorables, y disminuyó apreciablemente después del ajuste de la moneda brasileña en el marco del Plan Real (véase el anexo).

De confirmarse, el hecho de que una parte de las importaciones no registradas fuera consumida en el

CUADRO 6

Paraguay: Comercio registrado y no registrado

\begin{tabular}{|c|c|c|c|c|c|c|c|c|c|c|}
\hline & & \multicolumn{9}{|c|}{ A. En millones de dólares corrientes } \\
\hline & & 1989 & 1990 & 1991 & 1992 & 1993 & 1994 & 1995 & 1996 & 1997 \\
\hline & Exportaciones registradas & 1009.4 & 958.7 & 737.1 & 656.6 & 725.2 & 816.8 & 919.3 & 1043.4 & 1088.6 \\
\hline & Importaciones registradas & 660.8 & 1193.4 & 1275.4 & 1237.1 & 1477.5 & 2140.4 & 2782.2 & 2850.5 & 2957.1 \\
\hline & Exportaciones no registradas & 170.6 & 407.5 & 372.4 & 397.6 & 1103.4 & 1464.9 & 2111.1 & 1723.3 & 1554.8 \\
\hline & Importaciones no registradas & 355.1 & 442.4 & 592.2 & 688.2 & 1240.3 & 1411.3 & 1689 & 1345.1 & 1080 \\
\hline \multirow{3}{*}{\multicolumn{2}{|c|}{ 5. Déficit comercial no registrado (3-4) }} & -184.5 & -349.9 & -219.8 & -290.6 & -136.9 & 53.6 & 422.1 & 378.2 & 474.8 \\
\hline & & \multicolumn{9}{|c|}{ B. En porcentajes áe.1 PIB } \\
\hline & & 1989 & 1990 & 1991 & 1992 & 1993 & 1994 & 1995 & 1996 & 1997 \\
\hline & Exportaciones registradas & 24.5 & 18.1 & 11.8 & 10.2 & 10.6 & 10.4 & 10.2 & 10.8 & 10.9 \\
\hline & Importaciones registradas & 16.1 & 22.6 & 20.4 & 19.2 & 21,6 & 27.2 & 31.0 & 29.4 & 29.5 \\
\hline & Exportaciones no registradas & 4.1 & 7.7 & 6.0 & 6.2 & 15.5 & 17.8 & 23.3 & 17.8 & 15.5 \\
\hline & Importaciones no registradas & 8.6 & 8.4 & 9.5 & 10.7 & 18.0 & 17.9 & 19.2 & 13.9 & 10.8 \\
\hline & Déficit comercial no registrado (3-4) & -4.5 & -0.7 & -3.5 & -4.5 & -2.5 & - & 4.2 & 3.9 & 4.7 \\
\hline
\end{tabular}

Fuente: Banco Central del Paraguay, sobre la base de la Dirección de Comercio del Fondo Monetario Internacional. 
país en vez de destinarse a la reexportación sería coherente con la tesis del auge de consumo que surge del análisis de otros datos macroeconómicos. En efecto, si el mismo comercio no registrado se mantuvo deficitario en la primera parte de los años ochenta, la opción de las autoridades económicas por validar el modelo importador (con su componente adicional de reexportación) sobre todo a través de ventajas arancelarias y fiscales, pero también mediante la sobrevaluación de la moneda nacional, contribuyó a agravar los desequilibrios macroeconómicos generados por el crecimiento del consumo y el exceso de absorción interna. Además, el excesivo énfasis en el aprovechamiento de las desventajas competitivas de los países vecinos (proteccionismo, altos impuestos internos) por determinados grupos de interés se realizó a expensas del aprovechamiento de las ventajas comparativas propias, lo que contribuyó al escaso dinamismo de las unidades productivas locales.

El agotamiento del modelo importador a partir de 1995 con la entrada en vigor del MERCOSUR y el proceso de convergencia arancelaria, así como el progresi- vo bloqueo impuesto por las autoridades brasileñas y argentinas al comercio fronterizo, ha puesto al país ante el desafío de cambiar radicalmente su orientación de política económica hacia un esquema compatible con el fomento de una estrategia exportadora. ${ }^{7}$ Este proceso debe ser impulsado por los principales agentes económicos, pues no será automático. Parece inevitable que el proceso de convergencia arancelaria que se inició en 1995 lleve a la desaparición del comercio no registrado de reexportación, al ir reduciendo las diferencias de aranceles sobre bienes terminados en los distintos países del MERCOSUR. Sin embargo, Herken Krauer (1995), argumenta que dadas las características relativamente erráticas del proceso de integración (como la permanencia de barreras no arancelarias y las modificaciones especiales del arancel externo común), los factores determinantes del comercio seguirán siendo la tasa de cambio real, las barreras no arancelarias y la inestabilidad financiera y monetaria de los países miembros, por lo que el comercio de reexportación del Paraguay contaría aún con una base firme, aunque quizá sus márgenes de ganancia bajarían.

\section{IV}

\section{Evolución macroeconómica y sistema financiero}

Entre 1988 y 1992 se llevó a cabo en Paraguay un programa de reforma financiera orientado a liberalizar el sistema, pero que contempló sólo algunas de las medidas aplicadas en otros procesos de reforma en América Latina (cuadro 7).

Dos aspectos merecen consideración. En primer lugar, de las ocho medidas enumeradas en el cuadro 7 se aplicaron la liberalización de las tasas de interés y la reducción de los encajes legales. En segundo lugar, la secuencia de las medidas fue claramente inadecua$\mathrm{da}:^{8}$ mientras se liberalizaban estas variables financieras (a las que debe agregarse el tipo de cambio y la posibilidad de realizar operaciones en moneda extran-

\footnotetext{
${ }^{7}$ El compromiso de integración asumido por el país incluye evidentemente la obligación de aplicar políticas de control de las actividades ilícitas, pues seguir apostando paralelamente a un modelo de comercio informal generaría la oposición de los socios del MERCOSUR e imposibilitaría el desarrollo de tal modelo exportador. 8 Véase un examen de los procesos de reforma financiera en América Latina después de 1988 y una evaluación de la secuencia de tales reformas en BID, 1996.
}

jera), no se avanzaba en el proceso de saneamiento y supervisión de un sistema financiero hasta entonces marcado por graves distorsiones estructurales, entre ellas la costumbre de trabajar "sin riesgo" gracias a los redescuentos automáticos del Banco Central, y la formación de grandes carteras vinculadas en los principales grupos financiero-industrial-comerciales (DuarteGiménez, 1997). En este contexto de rápida liberalización sin un fortalecimiento concomitante de la supervisión prudencial, se gestaba la futura crisis financiera de $1995 .{ }^{9}$

La débil supervisión ejercida por la superintendencia de bancos en el periodo mencionado permitió que se elevara mucho el riesgo de las carteras de la mayoría de las entidades bancarias, plasmado en el rápido crecimiento del número de entidades y del monto del crédito global al sector privado. Entre 1989

\footnotetext{
v La segunda crisis financiera, de ;997, es considerada aquí como una continuación de lo ocurrido en 1995, debido a que no se tomaron las medidas de saneamiento oportunas.
} 
CUADRO 7

Paraguay: Medidas de reforma financiera entre 1988 y 1995

\begin{tabular}{|c|c|c|c|c|c|}
\hline \multicolumn{2}{|c|}{$\begin{array}{l}\text { Liberalización de } \\
\text { las tasas de interés }\end{array}$} & \multicolumn{2}{|c|}{ Cambio en los encajes' ${ }^{1}$} & \multirow{2}{*}{$\begin{array}{l}\% \text { del crédito } \\
\text { dirigido que } \\
\text { se mantiene }\end{array}$} & \multirow{2}{*}{$\begin{array}{l}\text { Privatización del } \\
\text { mercado de } \\
\text { préstamos (bancos } \\
\text { estatales) }\end{array}$} \\
\hline Pasivas & Activas & $\begin{array}{c}\text { Moneda } \\
\text { local }\end{array}$ & $\begin{array}{c}\text { Moneda } \\
\text { extranjera }\end{array}$ & & \\
\hline Sí & Sí & Menor & Igual & Subsiste en parte & No \\
\hline \multicolumn{2}{|c|}{$\begin{array}{l}\text { Mayor indepen- } \\
\text { dencia del } \\
\text { Banco Central }\end{array}$} & \multicolumn{2}{|c|}{$\begin{array}{l}\text { Mejoramiento de la } \\
\text { regulación del } \\
\text { mercado de capital }\end{array}$} & $\begin{array}{c}\text { Mejoramiento de } \\
\text { ¡a regulación } \\
\text { bancaria }\end{array}$ & $\begin{array}{l}\text { Mejoramiento de } \\
\text { la supervisión } \\
\text { bancaria }\end{array}$ \\
\hline \multicolumn{2}{|c|}{$\mathrm{No}^{11}$} & \multicolumn{2}{|c|}{$\mathrm{Si}^{\mathrm{c}}$} & $\mathrm{No}^{d}$ & $\mathrm{No}^{\circ}$ \\
\hline
\end{tabular}

* El encaje legal en moneda nacional fue reducido progresivamente, pasando del $42 \%$ en 1989 al $25 \%$ en 1994 (y $18 \%$ para los bancos que se comprometan a utilizar el diferencial para dar créditos al sector algodonero). Dicho nivel fue luego mantenido hasta 1996.

b A la fecha el Banco Central del Paraguay no tiene independencia legal ni técnica.

c Cabe notar que si bien existe la ley y a la fecha cotizan unas 60 empresas en el mercado bursátil, el movimiento de este mercado abarca esencialmente instrumentos del mercado de dinero.

¿ La nueva ley de bancos fue adoptada sólo en 1996, después de la crisis financiera de 1995.

c La supervisión bancaria necesita una reestructuración mayor, según la evaluación del BID (1996). A la fecha, esta aseveración aún es válida.

y 1994 se abrieron 13 nuevos bancos y 38 financieras, atraídos por la alta rentabilidad que las tasas libres dejaban entrever. ${ }^{10}$ En los primeros años hubo una concentración excesiva de riesgos en el sector exportador de soja y algodón, que llevó a un serio deterioro de las carteras activas durante tres años consecutivos de malas cosechas y precios internacionales deprimidos, lo que se complicó además por la creciente sobrevaluación de la moneda local con respecto al dólar. La necesaria reorientación de las actividades de crédito hacia otros sectores se vio retardada por una práctica perniciosa de la banca central, que, a pesar de haber eliminado oficialmente el redescuento dirigido, introdujo la reducción de encaje ligada al financiamiento del sector algodonero, perpetuando así el sistema anterior.

Los bancos que reorientaron sus carteras de crédito lo hicieron concentrándose en las actividades más lucrativas y a la vez más riesgosas: el crédito al con-

${ }^{10}$ El sobredimensionamiento del sistema financiero es más evidente si se considera que en 1994 había una entidad financiera (incluyendo bancos y financieras) por cada 47000 habitantes, A dicha fecha (antes de ja crisis financiera) existían 34 bancos y 65 financieras, a los que se sumaban varias cooperativas de ahorro y crédito, compañías de ahorro y préstamos para la vivienda, etc. sumo y las tarjetas de crédito, contribuyendo así a la burbuja de consumo de los años noventa. A la vez, el sistema financiero "negro" creció aceleradamente, merced a los escasos controles del ente de supervisión bancaria y de las autoridades tributarias. Una parte cada vez mayor de los depósitos captados se destinó a actividades ilícitas de alto rendimiento, como el contrabando, o a préstamos a tasas usurarias a comercios que trabajaban en actividades ilícitas ("en negro"). Como consecuencia, hubo fuertes alzas en las tasas de interés tanto pasivas como activas, impulsadas por la necesidad de captar cada vez más depósitos para financiar dichas actividades de alto riesgo. La garantía estatal implícita a los depósitos sirvió de acicate.

Este comportamiento se dio en la mayoría de los bancos y financieras de capital nacional. Sus malas prácticas de gestión (incluidas tanto la simple ineficiencia como las operaciones que escapaban a la legalidad) las llevaron a captar clientes — que eran más riesgosos- a tasas cada vez más elevadas, con el consiguiente deterioro de sus carteras activas. Además, parte de los recursos se prestaba a personas o empresas vinculadas a los dueños de los bancos involucrados, sin aplicar criterios de evaluación de proyectos, por lo cual muchas de estas entidades acumularon pérdidas importantes. 
$\mathrm{E}_{\mathrm{i}}$ sistema financiero estaba marcado, sin embargo, por una clara dualidad, ya que por otro lado hubo entidades, principalmente sucursales de bancos de capital extranjero, que supieron adecuarse a las circunstancias gracias a un mejor manejo administrativo, y limitaron tradicionalmente su oferta de crédito a clientes de primer nivel (empresas grandes, operaciones de comercio exterior con su país de origen). Este hecho, junto a la concentración de la banca nacional en actividades especulativas o de financiamiento del consumo, hizo que un gran segmento del sector productivo -las pequeñas y medianas empresas, sobre todo las que no estaban vinculadas a algún grupo financierotuviera poco acceso al crédito bancario durante el período considerado.

La teoría económica relativa al funcionamiento de los mercados financieros analiza los motivos que hacen del mercado del dinero un mercado complejo, en el cual el precio (la tasa de interés) no siempre se ajusta para equilibrar la oferta y la demanda y en el que pueden producirse equilibrios racionados (Stiglitz y Weiss, 1981), Existen en él efectos de "selección adversa" e "incitativos", que implican que las tasas de interés canalizan información relacionada no sólo con los niveles de la oferta y de la demanda, sino también con la calidad de los clientes. Esto se traduce en que la rentabilidad crece con la tasa de interés (aunque más lentamente) hasta un cierto nivel, más allá del cual la rentabilidad esperada decrece. De manera coherente con este fenómeno debido al efecto de selección adversa - los clientes dispuestos a pagar una tasa más elevada son los más riesgosos-, las entidades financieras racionales limitan su oferta de crédito, aunque exista demanda insatisfecha.

Además, debido a una situación de oligopolio tácito en el mercado financiero paraguayo, los bancos de capital extranjero no redujeron apreciablemente sus tasas, sino que las ubicaron sola un poco por debajo de las que aplicaban los intermediarios financieros más ineficientes o riesgosos, con lo cual lograron alta rentabilidad. De esta forma, las tasas de interés medias anuales se mantuvieron muy elevadas durante el período: tasas pasivas negativas y tasas activas reales que oscilaban entre 10 y $20 \%$, con diferencias de entre 15 y $20 \%$.

Por esta dicotomía del sistema y por la especialización de las instituciones bancarias, se vio racionado el crédito a determinados sectores, mientras se acrecentaba mucho para otras actividades de mayor rentabilidad, como el comercio, las finanzas y diversos negocios informales. Entre 1989 y 1995 se registró así un crecimiento rápido pero no desmesurado del crédito global, de 10.8 a $19.7 \%$ del PIB. La sostenibilidad de este crecimiento se aprecia mejor al relacionarlo con el grado de penetración de la actividad financiera. En términos reales, la razón entre la tasa de crecimiento del crédito y la tasa de crecimiento del PIB fue de 6.2 para el período (cuadro 8); esta cifra es algo superior a las registradas en otros países con un grado de penetración similar, como Argentina y Colombia (The Economist, 1997, p. 19).

Sin embargo, como se mencionó antes, el crecimiento del crédito fue más pronunciado en la banca privada nacional que en la banca extranjera y la banca pública, con tasas medias anuales de $32.2 \%, 14.4 \%$ y $14.7 \%$, respectivamente, en términos reales. Si se considera sólo la banca privada de capital nacional, la razón era de 10.4, nivel comparable al de México en el mismo período y muy superior al que se considera sostenible.

Por otro lado, las ingentes entradas de capitales registradas en el período fueron sólo parcialmente esterilizadas y alimentaron el auge del crédito de corto plazo a actividades de alto rendimiento, así como una sostenida afluencia de recursos hacia el sector inmobiliario." Una serie de decisiones de política económica tomadas a destiempo, como en particular la de liberar los fondos de las entidades públicas anteriormente depositados en el Banco Central sin regular adecuadamente las condiciones en que se colocarían, contribuyó a agravar la situación, pues dichos recursos se dirigieron a las entidades que ofrecían las tasas más elevadas.

CUADRO 8 Paraguay: Razón entre la tasa de
crecimiento del crédito y la tasa
de crecimiento del PIB, 1989-1995

\begin{tabular}{lr}
\hline Banca nacional & I0.4 \\
Banca extranjera & 4.6 \\
Banca pública & 4.7 \\
& \\
Total banca & 6.2 \\
\hline
\end{tabular}

Fuente: Elaboración propia con datos del Banco Central del Paraguay.

\footnotetext{
" Véase un análisis de la relación entre corrientes de capitales y sector financiero en Folkerts-Landau y otros, 1995.
} 


\section{V}

\section{Conclusión: Burbuja de consumo y crisis financiera}

En 1995, una conjunción de acontecimientos sometió a las entidades financieras más expuestas a una tensión excesiva. Entre éstos se puede mencionar la evolución desfavorable de los precios internacionales de la soja, que causó grandes pérdidas en algunas entidades excesivamente comprometidas en el financiamiento de la cosecha, y la reducción de las entradas de capitales luego de la crisis mexicana. Asimismo, en el orden interno, actuó como catalizador de la crisis el descubrimiento de un importante desfalco en la bóveda del Banco Central, originado en el desvío de fondos correspondientes al encaje legal de los bancos comerciales y en el cual habrían estado complicados representantes de dichas entidades privadas.

Bancos que a través de operaciones no registradas, actividades especulativas y préstamos vinculados habían acumulado pérdidas que sobrepasaban —en algunos casos varias veces- su patrimonio, se encontraron en situación de ¡liquidez y debieron enfrentar corridas de depositantes. El que se llegara a esta situación se debió en gran medida a fallas de la supervisión, ya que los balances de algunos de los bancos que debieron entonces ser intervenidos no habían sido aprobados por varios años, sin que se tomaran medidas al respecto.

Gavin y Hausmann (1995) interpretan las crisis financieras de muchos de los países latinoamericanos como el resultado de una perturbación de origen macroeconómico en condiciones de debilidad del sistema financiero, que hace que la "cadena" (el sistema) se rompa en su "eslabón" más frágil (los bancos afectados). En el caso del Paraguay, la fragilidad en cuestión resultaba principalmente de actividades de alto riesgo, ilícitas ("en negro") y de préstamos vinculados. A la luz de lo expuesto se puede sostener, sin embargo, que la crisis financiera de 1995 fue el síntoma del reventón de una burbuja de consumo, en gran parte vinculada al crecimiento del sector informal y de actividades financieras ilícitas, y alimentada por importantes entradas de capitales.

El corte en la cadena de pagos y créditos que siguió a los problemas financieros de 1995 se debió esencialmente al bloqueo del uso del cheque adelantado como instrumento de intercambio comercial y de crédito informal. En efecto, el cheque adelantado, entonces ilegal, se había convertido en el principal instrumento de crédito alternativo por la fuerza ejecutiva que le daba la pena de prisión ligada a la emisión de cheques sin fondos. A la vez, las entidades financieras habían desarrollado un mercado negro de redescuento de dicho instrumento a través de sus compañías financieras vinculadas. La caída de varios de los bancos activos en este negocio y la desconfianza del público en el sistema bancario se tradujeron entonces en un corte abrupto de dichas operaciones, que profundizó el impacto recesivo de la crisis.

En cuanto al contexto macroeconómico prevaleciente, al parecer las malas políticas, en el sentido de dejar crecer exageradamente el gasto por un lado y de descuidar la supervisión bancaria en un contexto de liberalización financiera por el otro, prepararon el terreno para tal crisis. Finalmente, la opción equivocada por un modelo importador y de triangulación comercial, permisivo para el comercio no registrado, contribuyó a profundizar los desequilibrios mencionados, lo que después de la crisis financiera de 1995 resultaría en un considerable ajuste recesivo. Las fallas de política económica que revela el comportamiento de las variables entre 1989 y 1995 apuntan a la necesidad de plantear una estrategia macroeconómica sostenible y orientada al crecimiento (CEPAL, 1995).

Además de sanear el sistema financiero y reforzar la supervisión bancaria, requisitos previos a toda estrategia macroeconómica sostenible, es necesario vigilar con más atención el gasto interno y regular adecuadamente los flujos de capitales. Asimismo, es preciso mejorar las estadísticas económicas (específicamente las del sector externo), condición ineludible e íntimamente ligada a una opción diferente de modelo económico.

En cuanto al fenómeno de las burbujas examinado aquí, queda pendiente un análisis más detallado de su aspecto organizacional-institucional (véase Nochteff, 1996). En efecto, en cada uno de los mercados mencionados dicho fenómeno aparece ligado al aprovechamiento de cuasi rentas de privilegio por grupos que disfrutaban de protecciones. Así, la persistencia de un 
modelo importador con importantes componentes de contrabando y reexportación — de contramano con la orientación declarada de liberalización y orientación exportadora-, se basó en la preservación de los beneficios de algunos agentes particulares y se realizó a expensas de un mayor aprovechamiento de las ventajas comparativas propias (Herken Krauer, 1995). Asi- mismo, durante varios años se ampararon numerosas prácticas inadecuadas en la esfera financiera, a pesar de existir indicios claros de su existencia, dando lugar a elevadas ganancias para determinados grupos económicos y al crecimiento de carteras de crédito en actividades no sostenibles, todo lo cual desembocó finalmente en la crisis financiera de 1995.

\section{Anexo \\ El problema de las estadísticas en el Paraguay y el caso del sector externo}

La poca fiabilidad de las estadísticas económicas en el Paraguay es un obstáculo para el análisis sistemático del desempeño de la economía paraguaya, pues obliga a recurrir, como en el presente artículo, a múltiples fuentes, no todas coherentes entre sí, y a llenar algunos vacíos con estimaciones.

En el sector monetario se dispone de una relativa abundancia de datos. Sin embargo, el elevado porcentaje de actividad no registrada, que quedó de manifiesto después de la crisis financiera de 1995, hace pensar que los indicadores monetarios sólo reflejan una parte de la realidad. Se sabe, por ejemplo, que muchas entidades financieras captaban tres tipos de depósitos: "blancos" (con recibo oficial y asiento en la contabilidad del banco), "grises" (con recibo oficial pero no registrados en la contabilidad) y "negros" ( asiento contable), lo que a su vez se reflejaba en tres tipos de libros contables correspondientes a cada nivel de depósitos (Banco Mundial, 1996). Se presume que con la desaparición de varios bancos muy activos en el mercado negro, esta situación habría mejorado después de 1995. El indicador más confiable es sin duda el índice de precios al consumidor, cuya base se renovó en 1995. No puede decirse lo mismo de los indicadores de agregados monetarios, debido a los problemas de registro en las fuentes del sistema financiero.

En cuanto al sector real y a las cuentas nacionales, existen registros sistemáticos, pero son muy imprecisos debido a las aproximaciones en su proceso de elaboración. La actividad no registrada de muchos agentes económicos que se ha descrito explica en parte su reticencia a proporcionar datos a las instituciones públicas. Como resultado, si bien el sistema de las cuentas nacionales se rige por procedimientos adecuados — desde 1997 se trabaja con el sistema de cuentas nacionales 1993, versión 4, de las Naciones Unidas-, carece en muchos casos de insumos confiables en la forma de datos empíricos. Se estima que tradicionalmente el producto interno bruto se ha subestimado mucho, en montos que, según las fuentes que se utilicen, varían entre 30 y $60 \%$.

Pero los datos que deben mirarse con mayor cautela son sin duda los del sector externo, por la ya larga tradición del país como centro del comercio no registrado en el cono sur latinoamericano. Los problemas surgen tanto por el no registro como por el subregistro del valor de las mercaderías declaradas. La única fuente disponible para tratar de corregir estas deficiencias son las estimaciones realizadas por la Dirección de Comercio del Fondo Monetario Internacional y publicadas por el Banco Central del Paraguay (cuadro 6). La metodología consiste en cruzar las informaciones oficiales paraguayas (los registros de aduanas) con datos oficiales de exportaciones al Paraguay e importaciones desde el Paraguay de los principales socios comerciales (Brasil, Argentina, Estados Unidos, Japón, la provincia china de Taiwán, etc.), con el fin de estimar las posibles omisiones y subestimaciones sobre la base de las discrepancias que se observen. Estos datos son los que se utilizan en la elaboración de las cuentas nacionales. Sin embargo, en el proceso sufren ajustes que hacen que, por ejemplo, el déficit externo (calculado tanto con referencia al PIB como al INB) no sea coincidente según se consideren las cifras de la balanza de pagos o las de las cuentas nacionales.

En el cuadro 4 se presenta una elaboración propia que intenta superar estas dificultades metodológicas. Se ha ajustado la parte inferior del cuadro, estimando el cambio de las reservas en guaraníes constantes a partir de su valor en dólares corrientes (sobre la base del tipo de cambio vigente y el índice de precios implícitos del PIB), y deduciendo a continuación la magnitud de la afluencia de capital 
a partir de este valor y del ahorro externo resultante de las cuentas nacionales (parte alta del cuadro). Se trata inevitablemente de una aproximación, pues no resulta factible el método recomendable, que consistiría en computar independientemente las dos partes del cuadro para comprobar la coincidencia.

En cuanto a la magnitud del comercio no registrado, el estudio de dichas estimaciones arroja como primera conclusión que la magnitud del comercio no registrado en Paraguay es descomunal: por ejemplo, en 1994 las exportaciones e importaciones no registradas estimadas representaban 179 y $66 \%$ de las exportaciones e importaciones registradas, respectivamente.

Por otro lado, según las mismas estimaciones, el balance del comercio no registrado fue deficitario entre 1989 y 1993, equilibrado en 1994 y superavitario a partir de 1995 (cuadro 6). Este resultado, crucial para el análisis macroeconómico, puede ser explicado intuitivamente por una serie de factores. En primer lugar, gracias a las condiciones cambiarías que prevalecían, el "contrabando" de productos brasileños destinados al consumo interno paraguayo (alimentos, productos de higiene, insumos para la construcción, etc.) tuvo su auge en el período que culminó en 1994 (cuando se revirtió la sobrevaluación del guaraní con respecto a la moneda brasileña con la introducción del Plan Real en ese país), lo que es coherente con el hecho de que parte de las importaciones no registradas quedaba en el país y no era reexportada. En segundo lugar, el año 1995 trajo consigo importantes cambios en las economías paraguaya y brasileña. En Paraguay se abrió un ciclo netamente recesivo, lo que redujo la capacidad del país de absorber importaciones. En Brasil, el inicio del Plan Real generó un auge de consumo y una apreciación de la moneda nacional, en tanto que la balanza comercial, superavitaria desde hacía años, se tornó deficitaria. Claramente, parte de las importaciones adicionales del Brasil provino del $\mathrm{Pa}$ raguay, no siempre en forma declarada. No obstante, junto con el plan de estabilización basado en el tipo de cambio se inició en 1995 el calendario de convergencia arancelaria del MERCOSUR; con esto los aranceles medios brasileños experimentaron fuertes reducciones, lo que probablemente significó un aumento considerable de las importaciones desde fuera de la zona. Estos factores tienden a reforzar la tesis de que las condiciones macroeconómicas vigentes entre 1989 y 1994 reforzaban el sesgo consumista de la economía paraguaya, y de que sí existió un déficit, que sólo se revirtió después de 1994.

Sobre la base de este análisis, tanto las estimaciones disponibles como la evolución de las variables macroeconómicas sugieren que hasta 1994 el comercio no registrado contribuyó a agravar el exceso de absorción interna descrito en el artículo, respaldando la tesis de una burbuja de consumo interno. Por último, cabe señalar que a partir de 1995 el superávit no registrado representó sólo una pequeña fracción del déficit registrado, manteniéndose entonces un importante exceso de absorción.

\section{Bibliografía}

Aninat, E. y C. Larraín (1996): Flujos de capitales: lecciones a partir de la experiencia chilena, Revista de la CEPAL, $\mathrm{N}^{\circ} 60$, LC/G.1943-P, Santiago de Chile, Comisión Económica para América Latina y el Caribe (CEPAL).

Banco Mundial (1996): Paraguay. The Rule of The State, Report 15044-PA., Washington D,C.

BID (Banco Interamericano de Desarrollo) (1996): La reforma financiera, Progreso económico y social en América latina. Informe i996, capítulo 4, Washington, D.C.

Campos, L. (1995): Costo del dinero en el Paraguay: de la administración burocrática de las tasas a su liberalización. Efectos sobre el mercado, serie Estudios, $\mathrm{N}^{\circ} 10$, Asunción, Centro Paraguayo para la Promoción de la Libertad Económica y de la Justicia Social (CEPPRO), diciembre.

CEPAL (1995): América Latina y el Caribe: políticas para mejorar la inserción en la economía mundial, LC/G,1800/Rev.l-P, Santiago de Chile. Publicación de las Naciones Unidas, $\mathrm{N}^{\mathrm{c}}$ de venta S.95.II.G.6.

CEPPRO (1994a): Proyecto de Carta Orgánica del Banco Central del Paraguay: comentarios críticos y propuestas, Asunción. (1994b): Proyecto de Ley General de Bancos, Financieras y Otras Entidades de Crédito: análisis crítico y comentarios, Asunción.

(1995): Informe económico ;994, Asunción, julio.

(1996): Informe económico j995, Asunción, julio.

Duarte-Giménez, G. (1997): Medidas equivocadas para una crisis mal comprendida, Suplemento económico del diario ABC color, Asunción, agosto.

Ffrench-Davis, R. (1996): Políticas macroeconómicas para el crecimiento, Revista de la CEPAL, №60, LC/G.1943-P, Santiago de Chile, CEPAL.

Folkerts-Landau, D. y otros (1995): Effects of capital flows on the domestic financial sectors in APEC developing countries, M. Khan y C. Reinharl (eds.), Capital Flows in the APEC Región, Occasional paper, $\mathrm{N}^{\circ} 122$, Washington D.C, Fondo Monetario Internacional (FMI).

Gavin, M. y R, Hausmann (1995): The Roots of Banking Clises: The Macroeconomic Context, Working paper series, $\mathrm{N}^{\circ} 318$, BID, Washington, D.C.

Gavin, M., R. Hausmann, R, Perottí y E. Talvi (1996): Managing Fiscal Policy in Latín America and the Caribbean: Volatilily, 
Procyclicality, and Limited Creditworthiness, Working paper series, $\mathrm{N}^{\circ} 326$, BID, Washington, D.C.

Held, G. (1994): ¿Liberalización o desarrollo financiero?, Revista de la CEPAL, $\mathrm{N}^{\mathrm{O}}$ 54, LC/G.1845-P, Santiago de Chile, CEPAL

Herken Krauer, J.C. (1995): Hacia una economía política de la integración en el Mercosur, serie Estudios, $\mathrm{N}^{\circ}$ 8, Asunción, CEPPRO, octubre.

Larraín, C. (1994): Modernización de la supervisión bancaria, Revista de la CEPAL, $\mathrm{N}^{\circ}$ 54, LC/G.1845-P, Santiago de Chile, CEPAL.

Masi, F. (1995): Paraguay y el Mercosur: posibilidades en un mercado ampliado, Asunción, Centro de Análisis y Difusión de Economía Paraguaya (CADEP), agosto.

Moon, H. (1997): Paraguay's march toward 21st century. A proposal for Paraguay's 5 year development plan, Asunción, julio, mimeo.
Nochteff, H. (1996): La experiencia argentina: ¿Desarrollo o sucesión de burbujas?, Revista de la CEPAL, № 59, LC/G. 1931-P, Santiago de Chile, CEPAL.

Rojas-Suárez, L. y S. Weibrod (1995): Financial Fragilities in Latín America. The 1980s and 1990s, Washington, D.C, FMI, octubre.

Stiglitz, J. y A, Weiss (1981): Credit rationing in markets with imperfect information, The American Economic Review, vol, 71, $\mathrm{N}^{\circ} 3$, Menasha, Wisconsin, American Economic Association,

Straub, S. (1996): Resultados económicos del año 1995, Revista enfoques, $\mathrm{N}^{\circ} 7$, Asunción, CEPPRO, julio.

The Economist (1995): Latín American finance. A survey, vol. 337, $\mathrm{N}^{\circ} 7944$, Londres, 9 de diciembre.

(1997): Banking in emerging markets. A survey, vol. 343 $\mathrm{N}^{\circ} 8012$, Londres, 12 de abril. 